\title{
(- OPEN ACCESS \\ Giant oesophageal gastrointestinal stromal tumour presenting with dyspnoea and clubbed fingers
}

\author{
Yurie Yamamoto, ${ }^{1}$ Yosuke Sasaki, ${ }^{2}$ Michio Kougame, ${ }^{1}$ Naobumi Tochigi ${ }^{3}$
}

${ }^{1}$ Department of

Gastroenterology, Toho

University Medical Center Omori Hospital, Ota-ku, Tokyo, Japan

${ }^{2}$ Department of General

Medicine and Emergency Care,

Toho Universtiy, School of

Medicine, Ota-ku, Tokyo, Japan

${ }^{3}$ Department of Surgical

Pathology, Toho University

Medical Center Omori Hospital,

Ota-ku, Tokyo, Japan

Correspondence to

Dr Yosuke Sasaki,

pqrstbb@yahoo.co.jp

Accepted 2 July 2017

CrossMark

To cite: Yamamoto $Y$, Sasaki Y, Kougame M, et al. BMJ Case Rep Published Online First: [please include Day Month Year]. doi:10.1136/bcr-2017220540

\section{SUMMARY}

Gastrointestinal stromal tumours (GISTs) are mesenchymal neoplasms of the gastrointestinal tract originating from the interstitial cells of Cajal. Giant oesophageal GISTs are rare since the oesophagus is rarely the primary site of GISTs, and they are usually diagnosed early due to complaints such as dysphagia. We present the case of a giant oesophageal GIST presenting with prominent clubbing. The case underlined the diagnostic importance of clubbing and the careful consideration of chemotherapy. Although clubbed fingers associated with GISTs are rare, our experience demonstrates the importance of physicians' recognition of clubbing as a paraneoplastic phenomenon for early diagnosis of malignancies since patients seldom notice their own clubbing by themselves. Chemotherapy using imatinib, an Bcr-Abl kinase inhibitor, is the standard option for unresectable giant GISTs. However, careful consideration must be made of the risk of complications associated with rapid mass reduction due to imatinib such as bleeding, oesophageal perforation and mediastinitis.

\section{BACKGROUND}

Gastrointestinal stromal tumours (GISTs) are mesenchymal neoplasms of the gastrointestinal tract, which originate from the interstitial cells of Cajal and are characterised by expression of c-kit (CD117 antigen). The primary sites of GISTs are the stomach $(60 \%-70 \%)$, the small intestine $(25 \%-30 \%)$, the colon $(5 \%)$ and the oesophagus (2\%). ${ }^{1}$ Giant oesophageal GISTs are rare because the oesophagus is infrequently the primary site of GIST, and they rarely reach $20 \mathrm{~cm}$ since they are usually diagnosed earlier than those of the stomach due to complaints such as dysphagia. ${ }^{1-3}$ It is sometimes very difficult to discriminate the site of origin of giant GISTs because they tend to continuously invade the surrounding organs. Therefore, pathological diagnosis and evaluation using multimodalities help make the correct diagnosis. ${ }^{2}$

Chemotherapy using imatinib, a Bcr-Abl tyrosine kinase inhibitor, is the standard option for giant GISTs because of its high efficacy and the difficulty of surgical removal. ${ }^{14-8}$ However, rapid reduction of the mass due to imatinib often cause critical complications including bleeding or perforation of the necrotised gastrointestinal organs, which have made the indication of this agent for giant GISTs unclear; clinicians must therefore cautiously consider the indication. ${ }^{6910}$
Clubbing is mostly associated with bronchogenic carcinoma, malignant mesothelioma, pleural fibroma, metastatic osteogenic disease or inflammatory bowel disease. ${ }^{11}$ On the other hand, reports on clubbing associated with GISTs are few. ${ }^{12} 13$

We report a case of a giant oesophageal GIST presenting with prominent clubbing and dyspnoea without digestive organ symptoms. Our report suggests that clubbing can be a diagnostic clue for GISTs lacking digestive symptoms as well-known associated tumours such as bronchogenic carcinoma.

\section{CASE PRESENTATION}

A 68-year-old Japanese man visited our hospital complaining of severe dyspnoea. He had become unable to eat properly and became hypoactive 3 months before being hospitalised. He started feeling dyspnoea during trivial daily activities a month prior to admission. A week prior to admission, he became unable to walk or even move by himself because of dyspnoea and fatigue. Despite repeated advice to visit a hospital by his family, he refused. Finally, his common-law wife called an ambulance to our hospital. He had a medical history of herpes zoster and had undergone upper gastrointestinal endoscopy 7 years prior as a work-up for transient epigastric discomfort, yet the result was normal. Otherwise, he had never visited hospitals or had regular health check-ups. He had a smoking history of one pack of cigarettes a day over a 50-year period.

On physical examination, he appeared extremely ill and his vital signs indicated he was in shock; the blood pressure and heart rate were $79 / 63 \mathrm{~mm} \mathrm{Hg}$ and $117 \mathrm{bpm}$ (regular), respectively. Examinations of the extremities were remarkable for symmetric clubbing at the fingers and the toes (figure 1) with fast-pitting oedema and peripheral coldness. Laboratory data on admission was characteristic of a high inflammatory response, with hypoproteinaemia (Alb $1.5 \mathrm{~g} / \mathrm{dL}$ ) and anaemia with haemoglobin of $7.0 \mathrm{~g} / \mathrm{dL}$. Tumour makers (carcinoembryonic antigen, CA19-9 and alpha-fetoprotein) were within the normal ranges.

\section{INVESTIGATIONS}

CT of the trunk showed a large mass $23 \mathrm{~cm} \times 18 \mathrm{~cm} \times 20 \mathrm{~cm}$ in size, which extended from a bronchial bifurcation to the bilateral diaphragms, pressing the lungs and the heart (figure 2). The tumour diffusely involved surrounding tissues. 


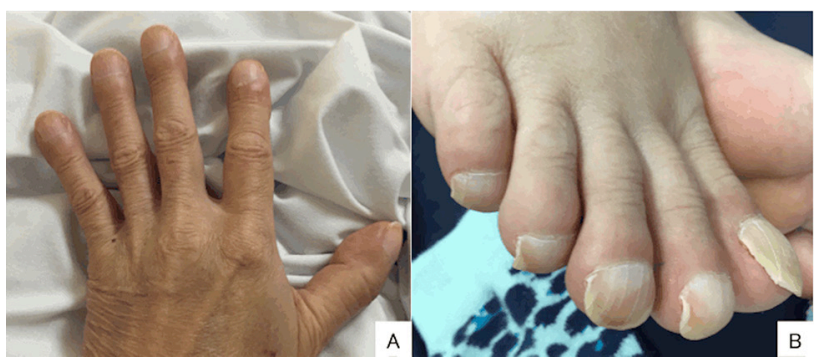

Figure 1 Clubbing of the fingers and toes. Symmetric clubbing was found in the fingers $(A)$ and toes $(B)$.

Because of an air-fluid level in the mass, necrosis of the tumour tissue was suspected (figure 2). Metastases to the liver were also found (figure 3). Upper gastrointestinal endoscopy found a mass located at the oral end of the oesophagogastric junction. The mass grew into the oral end looking like a round column (figure 4). We performed a biopsy of the ulcer located at the top of the columnar nodule. The specimen showed spindle cells consistent with GISTs. Immunostaining was positive for c-kit (CD117 antigen) and CD34, and was negative for alpha-smooth muscle actin and S100, which histologically confirmed the diagnosis of GIST (figure 5).

\section{DIFFERENTIAL DIAGNOSIS}

Because the tumour diffusely involved surrounding tissues, detection of the primary site was not easy. At first, the constellation of dyspnoea, smoking history, remarkable digital clubbing and mediastinal mass made us consider lung cancer and bronchogenic tumour as differential diagnoses rather than oesophageal GIST. Endoscopic and pathological findings were very useful for making the correct diagnosis.

\section{TREATMENT}

According to the current guidelines, chemotherapy with imatinib should be the first-line treatment in our case because of the unresectable size of the primary mass and the hepatic metastases. However, we carefully reviewed imaging studies and withheld the treatment because drastic reduction of the tumour caused by imatinib can cause bleeding or perforation of the invaded gut. After discussion of the treatment options with the patient and his family, we decided to provide best supportive care to the patient without radical treatments.

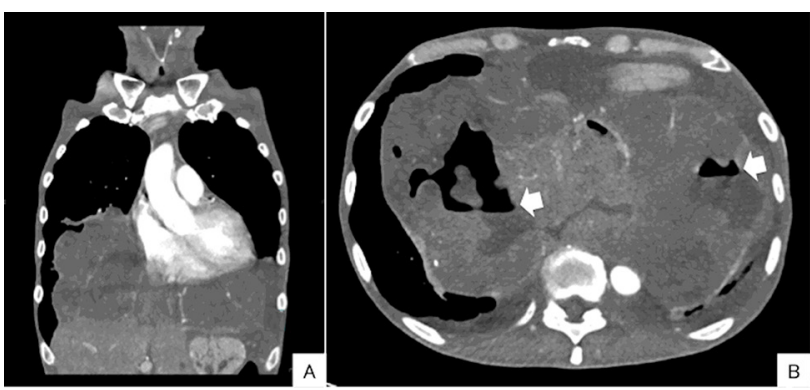

Figure 2 CT scans of the trunk. A large mass $(23 \mathrm{~cm} \times 18 \mathrm{~cm} \times 20 \mathrm{~cm})$ extends from a bronchial bifurcation to the bilateral diaphragms pressing the lungs and the heart and diffusely involving surrounding tissues (A). Air-fluid levels are shown in the mass (B, arrows), which suggests necrosis of the tumour.

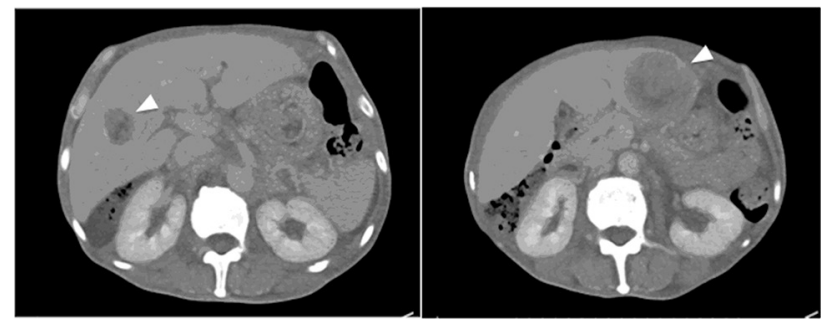

Figure 3 Liver metastases of the tumour. Low density round masses are shown in the bilateral lobes of the liver (triangles).

\section{OUTCOME AND FOLLOW-UP}

The patient passed away 19 days after the admission.

\section{DISCUSSION}

We experienced a rare case of giant GIST of the oesophagus presenting with prominent clubbing. Based on the experience, we would like to discuss the association of clubbing and GIST and the indication for imatinib in patients with giant GIST.

Although benign hereditary conditions can cause clubbing, clubbing sometimes provides important diagnostic clues to underlying infectious, neoplastic, inflammatory and vascular diseases in adults. ${ }^{11}$ Therefore, careful consideration of the underlying aetiology is required. Although many aetiologies, including genetic predisposition, parasympathetic neural mechanisms and the direct effect of tissue hypoxia have been proposed to explain the pathogenesis of clubbing, the exact aetiology has not yet been determined. ${ }^{11} 14$

Clubbing is generally known to be associated with bronchogenic carcinoma, malignant mesothelioma, pleural fibroma and metastatic osteogenic sarcoma. However, other malignancies also can cause clubbing. Clubbing associated with GIST is rare. Silva et al reported a case of GIST of the stomach presenting with clubbing as part of hypertrophic osteopathy. ${ }^{12}$ Axel et al also reported a case that was similar to our case; the patient presented with clubbing and body weight loss without digestive symptoms and was eventually diagnosed with GIST of the oesophagus. ${ }^{13}$ As we suggested, Axel et al advocate that

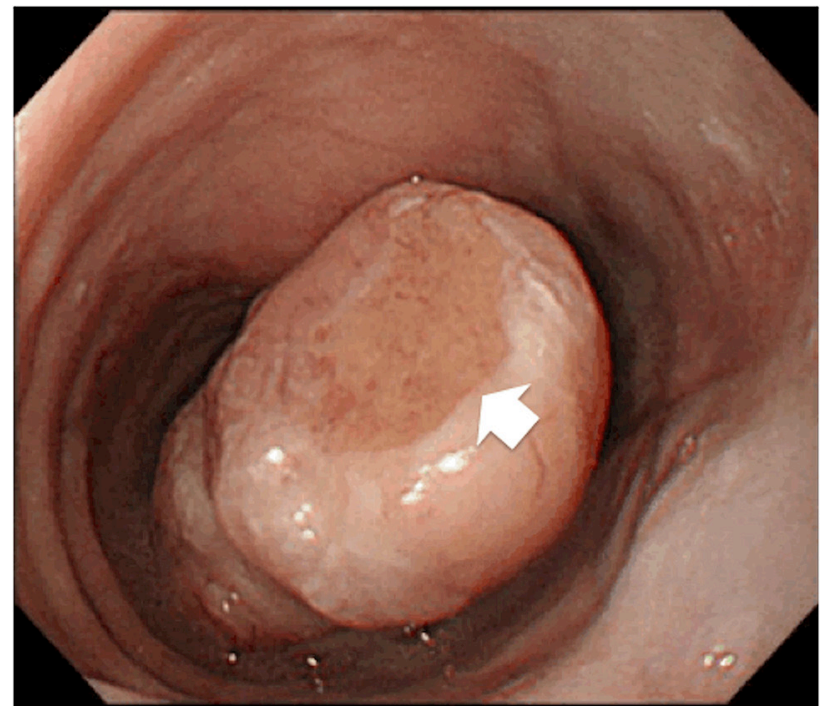

Figure 4 Endoscopic findings of the oesophageal mass. The mass at the oral end of the oesophagogastric junction grows into the oral side appearing as a round column. The top of the column is ulcerated (arrow). 


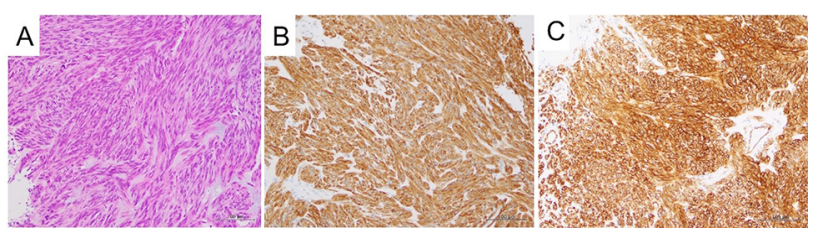

Figure 5 Histopathological findings of the tumour. H\&E staining (A) shows that spindle cells densely proliferate. Immunostaining of c-kit (B) and CD34 (C) shows diffuse dark-brownish deposition at the cytoplasm of the spindle tumour cells.

recognition of paraneoplastic phenomena, including clubbing, assists in making an earlier diagnosis of malignancies. Given that patients seldom notice their own clubbing by themselves, recognition of clubbing on careful examination of the extremities is required by clinicians. ${ }^{11}$

Imatinib, a tyrosine kinase inhibitor, was originally developed as a drug for chronic myeloid leukaemia, a disease caused by a Bcr-Abl mutation. Because imatinib inhibits the tyrosine kinase activity of KIT and Platelet-derived growth factor receptor (PDGFR) by competitively inhibit the binding between kinase and ATP, it has also been used for GISTs.

If resectable, surgical removal is the standard treatment for GISTs. Imatinib is the standard option for inoperable cases because of the drastic improvement in outcomes; imatinib reportedly achieved a 2-year event-free survival and 5-year mean overall survival. ${ }^{8}$ Before the introduction of imatinib, the mean survival was only 9-12 months. Combined use of imatinib with surgical removal has been also considered, since mass reduction due to imatinib may enable surgical removal of the tumour. ${ }^{15}$

\section{Patient's perspective}

Written by the patient's younger sister. (Translated by the corresponding author.)

I was surprised by the rarity and the rapid course of the illness. I am, however, satisfied with the medical management because my brother's preference was respected, and he passed away without prolonged suffering. I feel happy if our experience will be shared to other medical staffs to improve patients care they provide in the future.

Learning points

- Giant gastrointestinal stromal tumours (GIST) of the oesophagus can manifest as a mediastinal mass presenting with dyspnoea without digestive symptoms.

- GIST can cause digital clubbing.

- Recognition of clubbing can be a clue to the early diagnosis of oesophageal GIST lacking typical symptoms such as dysphagia.

- Clinician should recognise and explain the benefit and risk of imatinib for patients with giant GIST because drastic mass reduction induced by imatinib can cause fatal complications such as bleeding or perforation.

- The patient's preference must be taken into consideration.
On the other hand, rapid mass reduction often causes critical complications including bleeding or perforation of the necrotised gastrointestinal organs. ${ }^{610}$ A case of pleuritis and haemothorax associated with imatinib use was reported in Japan. ${ }^{9}$ In our case, the CT scan revealed diffuse adhesion to the surrounding tissues and air-fluid levels in the mass that indicates necrosis of the tumour. Given the CT findings, we thought the risk of complications associated with rapid mass reduction due to imatinib was high. We considered the risk of complications and the patient's preference and withheld imatinib for the patient.

Contributors $Y Y$ and $Y S$ managed the patient and wrote the article as a first author and a corresponding author. YS instructed YY as her mentor. MK managed the patient, performed endoscopy and biopsy and reviewed the previous reports on the management options of GIST as a coauthor. NT made diagnosis as a senior pathologist and gave some advices to other authors on the article. He also took pictures of the histopathological findings.

Competing interests None declared.

Patient consent Obtained.

Provenance and peer review Not commissioned; externally peer reviewed.

Open Access This is an Open Access article distributed in accordance with the Creative Commons Attribution Non Commercial (CC BY-NC 4.0) license, which permits others to distribute, remix, adapt, build upon this work non-commercially, and license their derivative works on different terms, provided the original work is properly cited and the use is non-commercial. See: http://creativecommons.org/ licenses/by-nc/4.0/

(C) BMJ Publishing Group Ltd (unless otherwise stated in the text of the article) . All rights reserved. No commercial use is permitted unless otherwise expressly granted.

\section{REFERENCES}

1 Miettinen M, Majidi M, Lasota J. Pathology and diagnostic criteria of gastrointestinal stromal tumors (GISTs): a review. Eur J Cancer 2002;38(Suppl 5):S39-S51.

2 Kato A, Oshima T, Hasegawa S, et al. Resection of a giant esophageal gastrointestinal stromal tumor with a gastric gastrointestinal Stromal tumor. Japanese J Gastroenterol Surg 2012;45:905-13.

3 Kafeel M, Cheedella NK, Wang JC. Esophageal gastrointestinal stromal tumors presenting as mediastinal mass. Case Rep Oncol 2013;6:579-84.

4 Joensuu H, Roberts PJ, Sarlomo-Rikala M, et al. Effect of the tyrosine kinase inhibitor STI571 in a patient with a metastatic gastrointestinal stromal tumor. N Engl J Med 2001;344:1052-6.

5 van Oosterom AT, Judson I, Verweij J, et al. Safety and efficacy of imatinib (STI571) in metastatic gastrointestinal stromal tumours: a phase I study. Lancet 2001:358:1421-3.

6 Demetri GD, von Mehren M, Blanke CD, et al. Efficacy and safety of imatinib mesylate in advanced gastrointestinal stromal tumors. N Engl J Med 2002:347:472-80.

7 Verweij J, Casali PG, Zalcberg J, et al. Progression-free survival in gastrointestinal stromal tumours with high-dose imatinib: randomised trial. Lancet 2004;364:1127-34.

8 Blanke CD, Rankin C, Demetri GD, et al. Phase III randomized, intergroup trial assessing imatinib mesylate at two dose levels in patients with unresectable or metastatic gastrointestinal stromal tumors expressing the kit receptor tyrosine kinase: s0033. J Clin Oncol 2008:26:626-32.

9 Kawamura T, Asakawa T, Kaneshiro M, et al. A patient with esophageal GIST who developed pleuritis after imatinib treatment. Progress Dig Endosc 2014;84:82-3.

10 Hecker A, Hecker B, Bassaly B, et al. Dramatic regression and bleeding of a duodenal GIST during preoperative imatinib therapy: case report and review. World J Surg Oncol 2010;8:47

11 Myers K, Farquhar D. Does This Patient Have Clubbing? In: Simel D, Rennie D, Keitz S, eds. JAMA: the Journal of the American Medical Association. New York: mcgraw Hill Medical, 2009:163-70.

12 Silva L, Andreu JL, Muñoz P, et al. Hypertrophic osteoarthropathy associated with gastrointestinal stromal tumour. Ann Rheum Dis 2006;65:681-2.

13 Axel J, Weickert U, Dancygier H. [Gastrointestinal tumor (GIST) of the esophagus in a 34-year-old man: clubbed fingers and alopecia arealis as an early paraneoplastic phenomenon]. Dtsch Med Wochenschr 2005:130:2380-3.

14 Horsfall FL. Congenital familial clubbing of the Fingers and Toes. Can Med Assoc J 1936:34:145-9.

15 DeMatteo RP, Lewis JJ, Leung D, et al. Two hundred gastrointestinal stromal tumors: recurrence patterns and prognostic factors for survival. Ann Surg 2000;231:51-8. 


\section{Unusual association of diseases/symptoms}

Copyright 2017 BMJ Publishing Group. All rights reserved. For permission to reuse any of this content visit http://group.bmj.com/group/rights-licensing/permissions.

BMJ Case Report Fellows may re-use this article for personal use and teaching without any further permission.

Become a Fellow of BMJ Case Reports today and you can:

- Submit as many cases as you like

- Enjoy fast sympathetic peer review and rapid publication of accepted articles

Access all the published articles

- Re-use any of the published material for personal use and teaching without further permission

For information on Institutional Fellowships contact consortiasales@bmjgroup.com

Visit casereports.bmj.com for more articles like this and to become a Fellow 